\title{
Antioxidative properties of tronchuda cabbage (Brassica oleracea L. var. costata DC) external leaves against DPPH, superoxide radical, hydroxyl radical and hypochlorous acid
}

\author{
Vendula Vrchovská ${ }^{\mathrm{a}}$, Carla Sousa ${ }^{\mathrm{b}}$, Patrícia Valentão ${ }^{\mathrm{b}}$, Federico Ferreres ${ }^{\mathrm{c}}$, \\ José A. Pereira $^{\mathrm{d}}$, Rosa M. Seabra ${ }^{\mathrm{b}}$, Paula B. Andrade ${ }^{\mathrm{b}, *}$ \\ ${ }^{a}$ Department of Pharmacognosy, Faculty of Pharmacy, Charles University, Heyrovského 1203, 50005 Hradec Králové, Czech Republic \\ ${ }^{\mathrm{b}}$ REQUIMTE/Serviço de Farmacognosia, Faculdade de Farmácia, Universidade do Porto, R. Aníbal Cunha, 164, 4050-047 Porto, Portugal \\ ${ }^{\mathrm{c}}$ Research Group on Quality, Safety and Bioactivity of Plant Foods, Department of Food Science and Technology, CEBAS (CSIC), \\ P.O. Box 164, 30100 Campus University of Espinardo, Murcia, Spain \\ d CIMOIESAB, Quinta de Sta Apolónia, Apartado 1172, 5301-855 Bragança, Portugal
}

Received 14 March 2005; received in revised form 8 June 2005; accepted 8 June 2005

\begin{abstract}
The ability of the aqueous extract of tronchuda cabbage (Brassica oleracea L. var. costata DC) external leaves to act as a scavenger of $\mathrm{DPPH}^{\cdot}$ and reactive oxygen species (superoxide radical, hydroxyl radical and hypochlorous acid) was investigated. A phytochemical study was also undertaken, and thirteen phenolic compounds and five organic acids were identified and quantified. Tronchuda cabbage extracts exhibited antioxidant capacity in a concentration-dependent manner in all assays, although some pro-oxidant effect was also noticed. The samples with higher phenolic and organic acid contents displayed the major antioxidant potentials.
\end{abstract}

(C) 2005 Elsevier Ltd. All rights reserved.

Keywords: Tronchuda cabbage; Brassica oleracea L. var. costata DC; DPPH; Superoxide radical; Hydroxyl radical; Hypochlorous acid; Phenolics; Organic acids

\section{Introduction}

Reactive oxygen species (ROS) are generated by many redox processes that normally occur in the metabolism of aerobic cells. If not eliminated, ROS can attack important biological molecules, such as lipids, proteins, enzymes, DNA and RNA (Jung, Park, Chung, Kim, \& Choi, 1999; Pietta, Simonetti, \& Mauri, 1998; Yen \& Chen, 1995). Although the human body possesses many defence mechanisms against oxidative stress, including antioxidant enzymes and non-enzymatic compounds,

\footnotetext{
* Corresponding author. Tel.: +351 222078935; fax: +351222003977.

E-mail address: pandrade@ff.up.pt (P.B. Andrade).
}

an excess of free radicals can go out of control, the organism being unable to scavenge all ROS (Halliwell, Aeschbach, Löliger, \& Aruoma, 1995; Miyake et al., 2000; Sies, 1993; Tseng et al., 1997). Their excess has been implicated in the development of chronic diseases, such as cancer, arteriosclerosis, nephritis, diabetes mellitus, rheumatism, ischemic and cardiovascular diseases and also in the ageing process (Behl \& Moosmann, 2002; Gyamfi, Yonamine, \& Aniya, 1999; Pulido, Bravo, \& Saura-Calixto, 2000). Oxidative stress can also play an important role in the development of neurodegenerative disorders, such as Alzheimer's and Parkinson's diseases (Behl \& Moosmann, 2002; Coulson, Siobhan, Cathal, Passmore, \& Johnston, 2004). There is convincing epidemiological evidence that the 
consumption of fruits and vegetables is, in general, beneficial for health, due to the protection provided by the antioxidant phytonutrients contained in them (Guthrie \& Kurowska, 2001). Especially vitamin C, vitamin E, carotenoids and dietary flavonoids can play important roles in human nutrition, and foods rich in these compounds should be involved in an optimal diet (du Toit, Volsteedt, \& Apostolides, 2001).

Brassicaceae vegetables are reported to reduce the risks of some cancers, especially due to their contents of glucosinolates and derived products (Beecher, 1994; Park \& Pezzuto, 2002; Stoewsand, 1995). Flavonoids and other phenolics are also considered to contribute to this capacity (Galati \& O'Brien, 2004; Hertog, Hollman, \& Van de Putte, 1993; Hollman, Hertog, \& Katan, 1996). The antioxidant activity of some Brassica oleracea varieties has already been investigated. Cauliflower has been assayed for the ability to scavenge DPPH* and $\mathrm{ABTS}^{+}$, as well as for ferric reducing efficiency and ability to inhibit lipid peroxidation (Llorach, Espín, Tomás-Barberán, \& Ferreres, 2003). The oxygen radical absorbance capacity values have been measured in broccoli (Kurilich, Jeffery, Juvik, Wallig, \& Klein, 2002; Ninfali \& Bacchiocca, 2003). To find the antiradical activity of white cabbage, hydroxyl radical was used (Racchi et al., 2002).

Tronchuda cabbage (B. oleracea $\mathrm{L}$. var. costata DC) is consumed throughout the world, being widely used in the preparation of soups. Its external leaves are rather bitter and tough and are usually prepared by boiling. The analysis of phenolics in tronchuda cabbage external leaves has already been done and fourteen phenolic compounds were identified and quantified (Ferreres et al., 2005). However, as far as we know, nothing has been reported about the antioxidant properties of tronchuda cabbage.

The aim of the present study was to evaluate the antioxidant potential of four tronchuda cabbage external leaves aqueous extracts, since this is the most common use of the species. Therefore, the capacity to act as scavenger of $\mathrm{DPPH}^{\cdot}$ and reactive oxygen species (superoxide radical, hydroxyl radical and hypochlorous acid) was investigated. In order to define the phenolic and organic acid compositions of the extracts, we caried out, respectively, HPLC/diode array (HPLC/DAD) and HPLC/ $\mathrm{UV}$ analysis. A possible relationship between chemical composition and antioxidant potential was established.

\section{Materials and methods}

\subsection{Standards and reagents}

The standards were from Sigma (St. Louis, MO, USA) and from Extrasynthése (Genay, France). Methanol and formic acid were obtained from Merck (Darms- tadt, Germany) and sulphuric acid from Pronalab (Lisboa, Portugal). The water was treated in a Milli-Q water purification system (Millipore, Bedford, MA, USA). DPPH, xanthine, xanthine oxidase (XO) grade I from buttermilk (EC 1.1.3.22), $\beta$-nicotinamide adenine dinucleotide (NADH), phenazine methosulfate (PMS), nitroblue tetrazolium chloride (NBT), anhydrous ferric chloride $\left(\mathrm{FeCl}_{3}\right)$, ethylenediaminetetraacetic acid disodium salt (EDTA), ascorbic acid, trichloroacetic acid, thiobarbituric acid, deoxyribose, sodium hypochlorite solution with $4 \%$ available chlorine $(\mathrm{NaOCl})$ and $5,5^{\prime}$ dithiobis(2-nitrobenzoic acid) (DTNB) were obtained from Sigma Chemical Co. (St. Louis, USA).

\subsection{Plant material and sampling}

Tronchuda cabbages grown by different agronomic practices and collected in two periods (Table 1) were studied. These samples were chosen among previously studied ones (Ferreres et al., 2005) because of their distinct phenolic composition. After harvesting, plants were immediately transported to the laboratory, where external and internal leaves were separated. Samples were stored in a freezer at $-20{ }^{\circ} \mathrm{C}$.

\subsection{Sample preparation}

Tronchuda cabbage external leaves extracts were prepared by pouring $600 \mathrm{ml}$ of boiling water on to $30 \mathrm{~g}$ of plant material. The mixture was boiled for one hour and then filtered through a Büchner funnel. The resulting extract was then lyophilised in a Labconco 4.5 apparatus (Kansas City, MO). The yields of the lyophilised extracts of samples A, B, C and D were 1.19, 1.07, 1.91 and $0.98 \mathrm{~g}$, respectively. The lyophilised extracts were kept in a desiccator, in the dark.

\subsection{HPLC analysis of organic acids}

The separation was carried out as previously reported (Silva, Andrade, Mendes, Seabra, \& Ferreira, 2002) with an analytical HPLC unit (Gilson), using an ion exclusion column Nucleogel ${ }^{\circledR}$ Ion 300 OA $(300 \times 7.7 \mathrm{~mm})$ column. Detection was performed with a UV detector set at $214 \mathrm{~nm}$.

Table 1

Characterization of tronchuda cabbage samples

\begin{tabular}{lll}
\hline Date of collection & Sample & Cultivation procedure \\
\hline November 2002 & A & Organic \\
& B & Conventional \\
December 2002 & C & Organic \\
& D & Conventional \\
\hline
\end{tabular}


Organic acids quantification was achieved by the absorbance recorded in the chromatograms relative to external standards.

\subsection{HPLC analysis of phenolics}

Twenty microlitres of each extract were analysed using a HPLC unit (Gilson) and a Spherisorb ODS2 reversedphase (Waters, Milford, USA) column $(250 \times 4.6 \mathrm{~mm}$, $5 \mu \mathrm{m}$ particle size) (Ferreres et al., 2005). The solvent system was a mixture of formic acid 5\% (A) and methanol (B), with a flow rate of $1 \mathrm{ml} \mathrm{min}^{-1}$, and the gradient was as follows: $0 \mathrm{~min}-10 \% \mathrm{~B}, 25 \mathrm{~min}-20 \% \mathrm{~B}, 40 \mathrm{~min}-$ $50 \%$ B, $45 \min -50 \%$ B, $46 \min -90 \%$ B, $50 \min -90 \%$ B, 55 min $-100 \%$ B, 58 min $-100 \%$ B, 60 min $-10 \%$ B. Detection was achieved with a Gilson diode array detector. Spectral data from all peaks were accumulated in the range of $200-400 \mathrm{~nm}$, and chromatograms were recorded at $330 \mathrm{~nm}$. The data were processed on a Unipoint system Software (Gilson Medical Electronics, Villiers le Bel, France). Peak purity was checked by the software contrast facilities.

Phenolic compounds quantification was achieved by the absorbance recorded in the chromatograms relative to external standards. With the exception of kaempferol 3-O-glucoside, which was quantified as itself, the identified compounds were quantified as kaempferol 3-O-rutinoside, if not commercially available.

\section{6. $D P P H^{\cdot}$ scavenging activity}

The antiradical activity of the extracts was determined spectrophotometrically in an ELX808 IU Ultra Microplate Reader (Bio-Tek Instruments, Inc.), by monitoring the disappearance of $\mathrm{DPPH}^{-}$at $515 \mathrm{~nm}$, according to a described procedure (Silva et al., 2004). For each extract, a dilution series (five different concentrations) was prepared in a 96 well plate. The reaction mixtures in the sample wells consisted of extract and DPPH radical dissolved in methanol. Three experiments were performed in triplicate.

\subsection{Evaluation of superoxide radical scavenging activity}

\subsubsection{General}

Antiradical activity was determined spectrophotometrically in an ELX808 IU Ultra Microplate Reader (Bio-Tek Instruments, Inc), by monitoring the effect of the lyophilised extracts on the $\mathrm{O}_{2}^{--}$-induced reduction of NBT at $562 \mathrm{~nm}$.

\subsubsection{Non-enzymatic assay}

Superoxide radicals were generated by the NADH/ PMS system according to a described procedure (Valentão et al., 2001). All components were dissolved in phos- phate $19 \mathrm{mM}$ buffer, $\mathrm{pH}$ 7.4. Three experiments were performed in triplicate.

\subsubsection{Enzymatic assay}

Superoxide radicals were generated by the xanthine/ xanthine oxidase (X/XO) system, following a described procedure (Valentão et al., 2001). Xanthine was dissolved in $1 \mu \mathrm{M} \mathrm{NaOH}$ and subsequently in phosphate $50 \mathrm{mM}$ buffer with $0.1 \mathrm{mM}$ EDTA, pH 7.8 , xanthine oxidase in $0.1 \mathrm{mM}$ EDTA and the other components in $50 \mathrm{mM}$ phosphate buffer with $0.1 \mathrm{mM}$ EDTA, pH 7.8. Three experiments were performed in triplicate.

\subsection{Effect on xanthine oxidase activity}

The effect of the lyophilised extracts on xanthine oxidase activity was evaluated by measuring the formation of uric acid from xanthine in a double beam spectrophotometer (Helios $\alpha$, Unicam), at room temperature. The reaction mixtures contained the same proportion of components as in the enzymatic assay for superoxide radical scavenging activity, except NBT, in a final volume of $600 \mu \mathrm{l}$. The absorbance was measured at $295 \mathrm{~nm}$ for $2 \mathrm{~min}$. Three experiments were performed in triplicate.

\subsection{Hydroxyl radical assay}

The deoxyribose method for determining the scavenging effect of the aqueous extracts on hydroxyl radicals was performed according to a described procedure (Valentão et al., 2002) in a double beam spectrophotometer (Helios $\alpha$, Unicam). Reaction mixtures contained ascorbic acid, $\mathrm{FeCl}_{3}$, EDTA, $\mathrm{H}_{2} \mathrm{O}_{2}$, deoxyribose and lyophilised extracts. All components were dissolved in $10 \mathrm{mM} \mathrm{KH}_{2} \mathrm{PO}_{4}-\mathrm{KOH}$ buffer, $\mathrm{pH}$ 7.4. This assay was also performed either without ascorbic acid or EDTA, in order to evaluate the extracts, pro-oxidant and metal chelation potentials, respectively. Three experiments were performed in triplicate.

\subsection{Hypochlorous acid scavenging activity}

The inhibition of hypochlorous acid-induced 5-thio2-nitrobenzoic acid (TNB) oxidation to 5,5'-dithiobis(2-nitrobenzoic acid) was performed according to a described procedure (Valentão et al., 2002), in a double beam spectrophotometer (Helios $\alpha$, Unicam). Hypochlorous acid and TNB were prepared immediately before use. Scavenging of hypochlorous acid was ascertained by using lipoic acid as a reference scavenger, which inhibited TNB oxidation in a concentrationdependent manner. Three experiments were performed in triplicate. 


\section{Results and discussion}

\subsection{Identification and quantification of phenolic compounds by HPLCIDAD}

The aqueous lyophilised extracts of tronchuda cabbage external leaves presented different phenolic compositions. In sample $\mathrm{D}$, only three compounds were detected: kaempferol 3-O-sophorotrioside, kaempferol 3-O-(sinapoyl)-sophoroside and kaempferol 3-O-(feruloyl)-sophorotrioside (Table 2). In sample $\mathrm{C}$, besides kaempferol 3-O-(feruloyl)-sophorotrioside, we identified kaempferol 3-O-sophoroside-7-O-glucoside, kaempferol 3-O-sophorotrioside-7-O-sophoroside, kaempferol 3-O(feruloyl)-sophoroside, kaempferol 3-O-sophoroside and kaempferol 3-O-glucoside (Table 2). Sample B showed all the compounds described above and kaempferol 3-O-sophorotrioside-7- $O$-glucoside, kaempferol 3$O$-(methoxycaffeoyl/caffeoyl)-sophoroside-7- $O$-glucoside, kaempferol 3-O-(sinapoyl/caffeoyl)-sophoroside-7-Oglucoside and kaempferol 3-O-(feruloyl/caffeoyl)-sophoroside-7- $O$-glucoside (Table 2). Sample A exhibited a chemical profile composed of the 12 above-mentioned kaempferol derivatives and kaempferol 3-O-sophoroside-7-O-sophoroside (Fig. 1 and Table 2). These compounds have already been identified in tronchuda cabbage external leaves methanolic extracts (Ferreres et al., 2005).

Sample A was the one with the highest amount of phenolics (ca. $1231 \mathrm{mg} / \mathrm{kg}$ ) (Table 2), kaempferol 3-O(feruloyl/caffeoyl)-sophoroside-7- $O$-glucoside being the main compound ( $26 \%$ of total identified compounds). Sample B had a lower phenolics content (ca. $32 \mathrm{mg} /$ $\mathrm{kg}$ ) (Table 2), in which kaempferol 3-O-sophoroside was the compound present in the highest amount (32\%). In sample D, kaempferol 3-O-(feruloyl)-sophoro- trioside was the major kaempferol derivative, while sample $\mathrm{C}$ exhibited only vestigial amounts of phenolics (Table 2).

As previously observed (Ferreres et al., 2005), when considering the evolution during winter, a decrease of the total phenolics content was noticed between November and December, which is more evident in samples from organic culture. The lowest level of total phenolics, observed in December in a sample from organic production, may be explained by the commitment of tronchuda cabbage cells to morphogenic developmental pathways, since those cabbages presented more developed leaves than those of conventional culture in the same period. In addition, samples from organic culture exhibited higher total phenolics content than those from conventional practices, collected in the same period, with the exception of the samples from December. This might be due to the interference of the mineral fertilizers and/or pesticides, used in conventional practices, in the biosinthetic pathway of flavonoids, decreasing phenolic amounts (Ferreres et al., 2005).

\subsection{Identification and quantification of organic acids by $H P L C / U V$}

Tronchuda cabbage external leaves had a chemical profile composed of five identified organic acids: citric, ascorbic, malic, shikimic and fumaric acids (Fig. 2). These compounds are reported for the first time in tronchuda cabbage. As observed for phenolic compounds, sample A exhibited the highest content of organic acids (ca. $55 \mathrm{~g} / \mathrm{kg}$ ) and sample $\mathrm{C}$ the lowest one (ca. $20 \mathrm{~g} / \mathrm{kg}$ ) (Table 3). In samples A, B and C, malic acid was the main compound, ranging from $37 \%$ to $78 \%$ of total identified organic acids, followed by citric acid (16$36 \%$ ) (Table 3). Sample D showed a distinct profile, in

Table 2

Phenolic composition of tronchuda cabbage external leaves ( $\mathrm{mg}$ of phenolic compound $\mathrm{kg}^{-1}$ of lyophilised extract) $)^{\mathrm{a}}$

\begin{tabular}{|c|c|c|c|c|c|c|c|c|}
\hline \multirow[t]{3}{*}{ Compounds $^{\mathrm{b}}$} & \multicolumn{8}{|c|}{ Samples } \\
\hline & \multicolumn{2}{|l|}{ A } & \multicolumn{2}{|l|}{$\mathrm{B}$} & \multicolumn{2}{|l|}{$\mathrm{C}$} & \multicolumn{2}{|l|}{$\mathrm{D}$} \\
\hline & Mean & SD & Mean & SD & Mean & SD & Mean & SD \\
\hline $\mathbf{1}+\mathbf{2}(\mathrm{RT} 24.0,24.2 \mathrm{~min})$ & 73.1 & 2.1 & nq & - & nd & - & nd & - \\
\hline $3+\mathbf{4}(\mathrm{Rt} 25.8,26.0 \mathrm{~min})$ & 237 & 5.2 & 8.2 & 0.5 & $\mathrm{nq}$ & - & nd & - \\
\hline 5 (RT $27.8 \mathrm{~min})$ & 46.3 & 6.9 & nd & - & nd & - & nd & - \\
\hline 6 (RT 30.7 min) & 119 & 5.9 & $\mathrm{nq}$ & - & nd & - & nd & - \\
\hline 7 (RT $31.2 \mathrm{~min}$ ) & 323 & 7.0 & 2.5 & 0.1 & nd & - & nd & - \\
\hline 8 (RT 36.5 min) & 26.1 & 0.1 & nq & - & nd & - & $\mathrm{nq}$ & - \\
\hline 9 (RT $37.4 \mathrm{~min})$ & nq & - & 2.6 & 0.0 & nd & - & $\mathrm{nq}$ & - \\
\hline 10 (RT $38.5 \mathrm{~min}$ ) & 85.8 & 1.5 & 7.4 & 0.0 & $\mathrm{nq}$ & - & 5.9 & 0.5 \\
\hline 11 (RT $39.3 \mathrm{~min}$ ) & 99.8 & 1.8 & 1.3 & 0.1 & $\mathrm{nq}$ & - & nd & - \\
\hline 12 (RT 39.7 min) & 221 & 5.2 & 10.6 & 0.1 & $\mathrm{nq}$ & - & nd & - \\
\hline 13 (RT $44.1 \mathrm{~min}$ ) & $\mathrm{nq}$ & - & nq & - & $\mathrm{nq}$ & - & nd & - \\
\hline$\Sigma$ & \multicolumn{2}{|c|}{1231.2} & \multicolumn{2}{|c|}{32.6} & \multicolumn{2}{|c|}{-} & \multicolumn{2}{|c|}{5.9} \\
\hline
\end{tabular}

${ }^{\text {a }}$ Results are expressed as means of three determinations. SD, standard deviation, $\sum$, sum of the determined phenolic compounds.

${ }^{\mathrm{b}}$ Identity of compounds as in Fig. 1. 


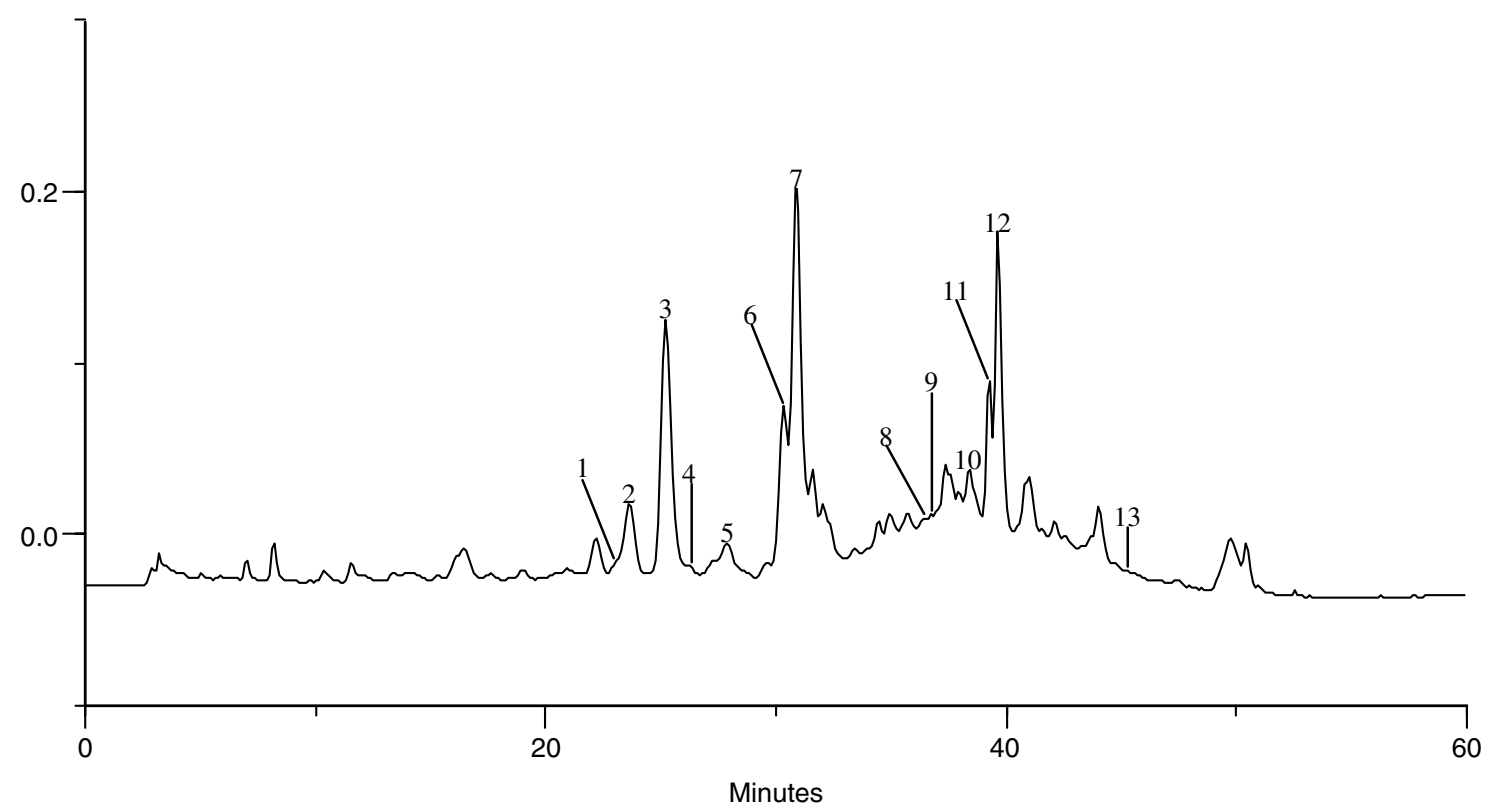

Fig. 1. HPLC phenolic profile of tronchuda cabbage external leaves. Detection at $330 \mathrm{~nm}$. Peaks: (1) kaempferol 3-O-sophorotrioside-7- $O$-glucoside; (2) kaempferol 3-O-(methoxycaffeoyl/caffeoyl)-sophoroside-7- $O$-glucoside; (3) kaempferol 3-O-sophoroside-7- $O$-glucoside; (4) kaempferol 3- $O$-sophorotrioside-7- $O$-sophoroside; (5) kaempferol 3- $O$-sophoroside-7- $O$-sophoroside; (6) kaempferol 3- $O$-(sinapoyl/caffeoyl)-sophoroside-7- $O$-glucoside; (7) kaempferol 3-O-(feruloyl/caffeoyl)-sophoroside-7-O-glucoside; (8) kaempferol 3-O-sophorotrioside; (9) kaempferol 3-O-(sinapoyl)-sophoroside; (10) kaempferol 3-O-(feruloyl)-sophorotrioside; (11) kaempferol 3-O-(feruloyl)-sophoroside; (12) kaempferol 3-O-sophoroside; (13) kaempferol 3-Oglucoside.

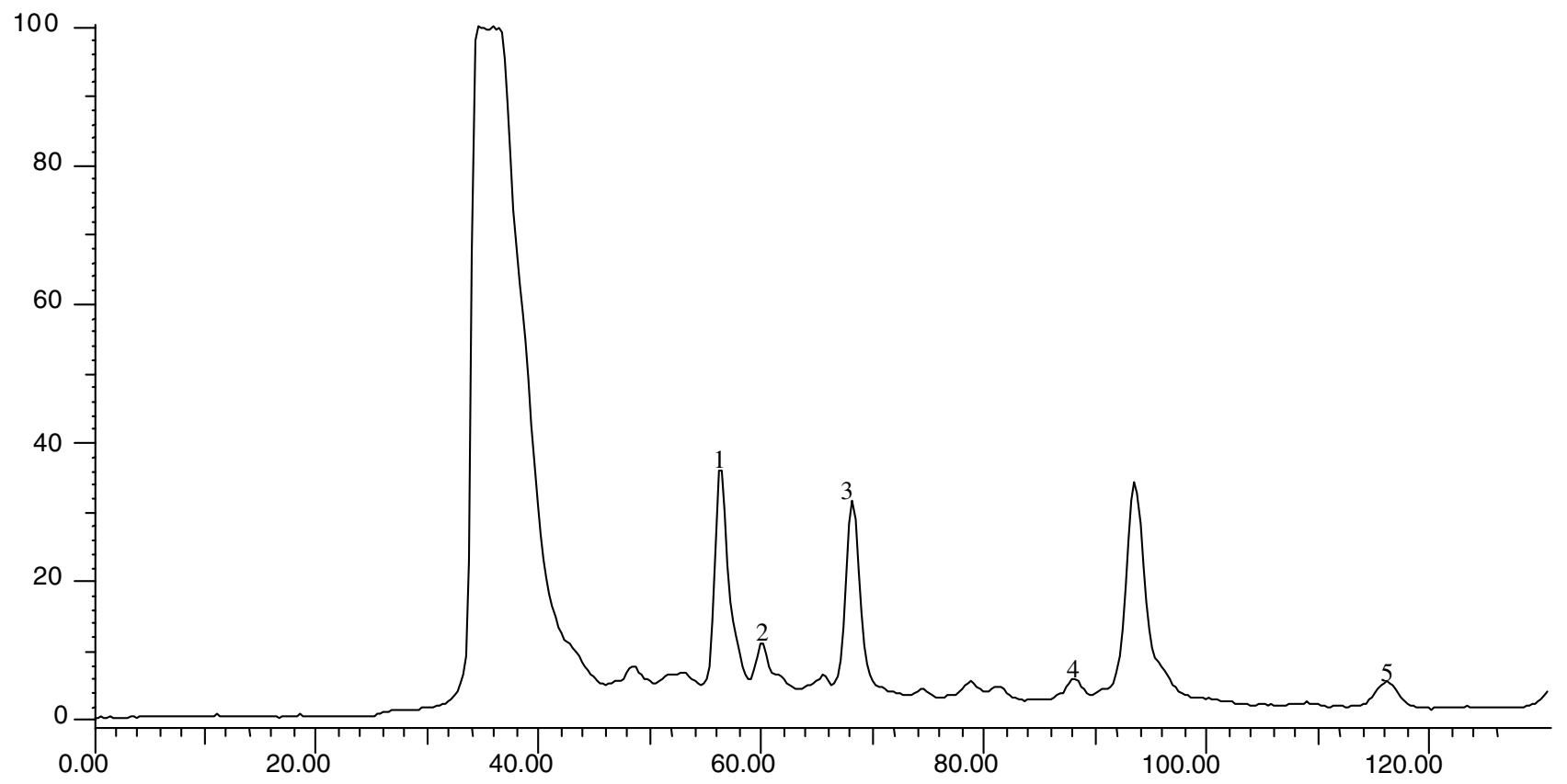

Fig. 2. HPLC organic acid profile of tronchuda cabbage external leaves. Detection at $214 \mathrm{~nm}$. Peaks: (1) citric acid; (2) ascorbic acid; (3) malic acid; (4) shikimic acid; (5) fumaric acid.

which ascorbic acid was the acid present in highest amounts representing $44 \%$ of total compounds, followed by malic acid (39\%) (Table 3). In all samples, shikimic and fumaric acids were minor compounds (Table 3).

\subsection{Antioxidant activity}

Antioxidant capacities of tronchuda cabbage external leaves aqueous lyophilised extracts are shown in Table 4 
Table 3

Organic acids in tronchuda cabbage external leaves ( $\mathrm{mg}$ of organic acid $\mathrm{kg}^{-1}$ of lyophilised extract) ${ }^{\mathrm{a}}$

\begin{tabular}{|c|c|c|c|c|c|c|c|c|}
\hline \multirow[t]{3}{*}{ Compound $^{\mathrm{b}}$} & \multicolumn{8}{|l|}{ Samples } \\
\hline & \multicolumn{2}{|l|}{ A } & \multicolumn{2}{|l|}{ B } & \multicolumn{2}{|l|}{$\mathrm{C}$} & \multicolumn{2}{|l|}{$\mathrm{D}$} \\
\hline & Mean & SD & Mean & SD & Mean & SD & Mean & SD \\
\hline $1(\mathrm{RT} 56.7 \mathrm{~min})$ & 18464 & 52.2 & 9101 & 172 & 3312 & 185 & 6770 & 3.0 \\
\hline $2(\mathrm{RT} 60.1 \mathrm{~min})$ & 10609 & 12.1 & 2937 & 2.8 & 1028 & 146.3 & 17343 & 206 \\
\hline 3 (RT 68.6 min) & 20506 & 57.3 & 13385 & 171 & 15472 & 286.9 & 15274 & 222 \\
\hline $4(\mathrm{RT} 88.9 \mathrm{~min})$ & 24.1 & 0.2 & 17.3 & 2.0 & 31.7 & 1.3 & 34.0 & 3.8 \\
\hline 5 (RT $116.8 \mathrm{~min})$ & 5336 & 115 & 27.7 & 0.1 & 111 & 0.0 & 58.0 & 1.0 \\
\hline$\Sigma$ & \multicolumn{2}{|c|}{54939} & \multicolumn{2}{|c|}{25468} & \multicolumn{2}{|c|}{19954} & \multicolumn{2}{|c|}{39479} \\
\hline
\end{tabular}

a Results are expressed as means of three determinations: SD, standard deviation, $\sum$, sum of the determined organic acids.

b Identity of compounds as in Fig. 2.

Table 4

$\mathrm{IC}_{25}$ values $\left(\mathrm{mg} \mathrm{ml}^{-1}\right)$ of tronchuda cabbage external leaves in antiradical assays

\begin{tabular}{lllll}
\hline Samples & $\begin{array}{l}\mathrm{DPPH} \\
\mathrm{IC}_{25}\end{array}$ & $\begin{array}{l}\mathrm{O}_{2}^{*-} \text { (non-enzymatic) } \\
\mathrm{IC}_{25}\end{array}$ & $\begin{array}{l}\mathrm{O}_{2}^{--} \text {(enzymatic) } \\
\mathrm{IC}_{25}\end{array}$ & $\begin{array}{l}\cdot \mathrm{OH} \\
\mathrm{IC}_{25}\end{array}$ \\
\hline $\mathrm{A}$ & 0.681 & 0.102 & 0.047 & 0.019 \\
$\mathrm{~B}$ & 1.66 & 0.045 & 0.139 & 0.045 \\
$\mathrm{C}$ & 2.32 & 0.362 & 0.311 & 0.223 \\
$\mathrm{D}$ & 1.14 & 0.146 & 0.101 & 0.018 \\
\hline
\end{tabular}

and Figs. 3-6. The DPPH' test is a non-enzymatic method currently used to provide basic information on the ability of extracts to scavenge free radicals. Reduction of $\mathrm{DPPH}^{-}$by an antioxidant results in a loss of absorbance at $515 \mathrm{~nm}$ (Fukumoto \& Mazza, 2000). Our results indicated that sample A was the one with the highest antioxidant potential, measured by the DPPH assay, followed by samples D and B, respectively. Sample $C$ exhibited the lowest scavenging capacity (Table 4 and Fig. 3). The effects observed were concentration-dependent.

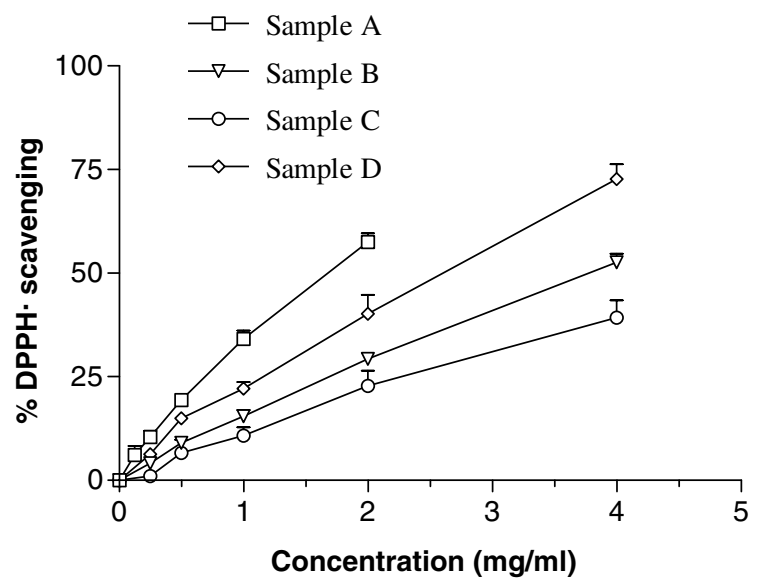

Fig. 3. Effect of tronchuda cabbage external leaves on DPPH reduction. Values show means $\pm \mathrm{SE}$ from 3 experiments performed in triplicate.
Superoxide radical is produced in vivo by activated phagocytes, by electron leakage from the mitochondrial electron transport chain (Halliwell, 1991) and in the conversion of xanthine to uric acid (Bast, Haenen, \& Doelman, 1991). The reactivity of this radical is limited but it is considered to be toxic. In fact, much of the molecular damage that can be done by superoxide radical is due to its conversion into much more reactive species, namely hydroxyl radical and peroxynitrite (Halliwell et al., 1995).

In the present work, the lyophilised extracts of tronchuda cabbage external leaves exhibited superoxide radical-scavenging activity using the $\mathrm{X} / \mathrm{XO}$ system in a concentration-dependent manner (Fig. 4(a)), sample A being the most active (Table 4). Bearing in mind that an inhibitory effect on the enzyme itself would also lead to a decrease of NBT reduction (Halliwell et al., 1995), the effect of the extracts on XO activity was checked. For this purpose a control experiment was performed evaluating the effect of tronchuda cabbage lyophilised extracts on the metabolic conversion of xanthine to uric acid. The results revealed that samples A, C and D had a weak inhibitory effect on $\mathrm{XO}$, while sample $\mathrm{B}$ presented higher inhibitory activity ( $\mathrm{IC}_{20}$ at $184 \mu \mathrm{g} / \mathrm{ml}$ ) (Fig. 4(b)), so it was not possible to show a clear-cut scavenging effect on superoxide radical. In view of clarification, the effect of the aqueous extracts on superoxide radical, generated by a chemical system composed of PMS, NADH and oxygen, was also evaluated. Under the assay conditions, all the samples were able to scavenge $\mathrm{O}_{2}^{--}$in a concentration-dependent way (Fig. 4(c)), in which sample B showed the strongest scavenging activity (Table 4).

Hydroxyl radical is the most reactive radical known: it can attack and damage almost every molecule found in living cells. Reactions of $\mathrm{OH}$ include its ability to interact with the purine and pyrimidine bases of DNA. It can also abstract hydrogen atoms from biological molecules, including thiols, leading to the formation of sulfur radicals able to combine with oxygen to generate oxysulfur radicals, a number of which damage biological molecules (Halliwell, 1991). The best-characterised 

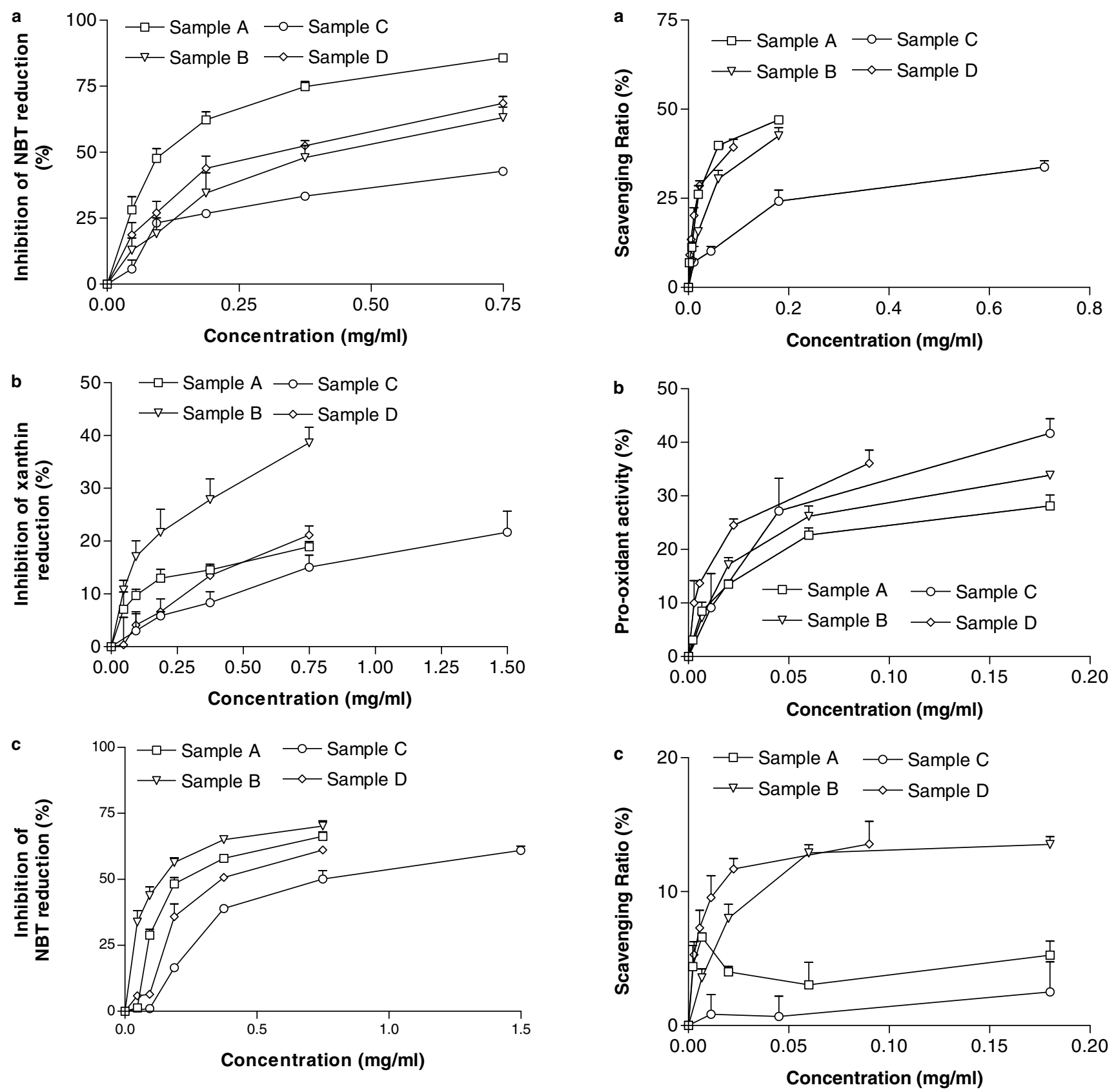

Fig. 4. Effect of tronchuda cabbage external leaves on: (a) NBT reduction induced by superoxide radical generated in a X/XO system; (b) on XO activity; (c) NBT reduction induced by superoxide radical generated in a NADH/PMS system. Values show means \pm SE from 3 experiments performed in triplicate.

biological damage caused by hydroxyl radical is its capacity to stimulate lipid peroxidation, which occurs when $\mathrm{OH}$ is generated close to membranes and attacks the fatty acid side chains of the membrane phospholipids (Halliwell, 1991).

Hydroxyl radicals are produced in vivo by Fentontype reactions, in which transition metals (e.g., iron) reduce hydrogen peroxide. Reducing agents, such as ascorbic acid, can accelerate $\mathrm{OH}$ formation by reducing $\mathrm{Fe}^{3+}$ ions to $\mathrm{Fe}^{2+}$ (Puppo, 1992). Deoxyribose is de-

Fig. 5. Effect of tronchuda cabbage external leaves: (a) non-specific hydroxyl radical-scavenging activity; (b) pro-oxidant activity (-AA); (c) specific hydroxyl radical-scavenging (-EDTA). Values show means $\pm \mathrm{SE}$ from 3 experiments performed in triplicate.

graded into malonaldehyde on exposure to hydroxyl radicals generated by Fenton systems. If the resulting mixture is heated under acid conditions, malonaldehyde may be detected by its ability to react with thiobarbituric acid to form a pink chromogen (Halliwell, Gutteridge, \& Aruoma, 1987). In the work herein, tronchuda cabbage lyophilised extracts exhibited scavenging activity for hydroxyl radical in a concentration dependent manner (Fig. 5(a)), with samples A and D presenting the highest capacity (Table 4). Sample C exhibited minor ability. 

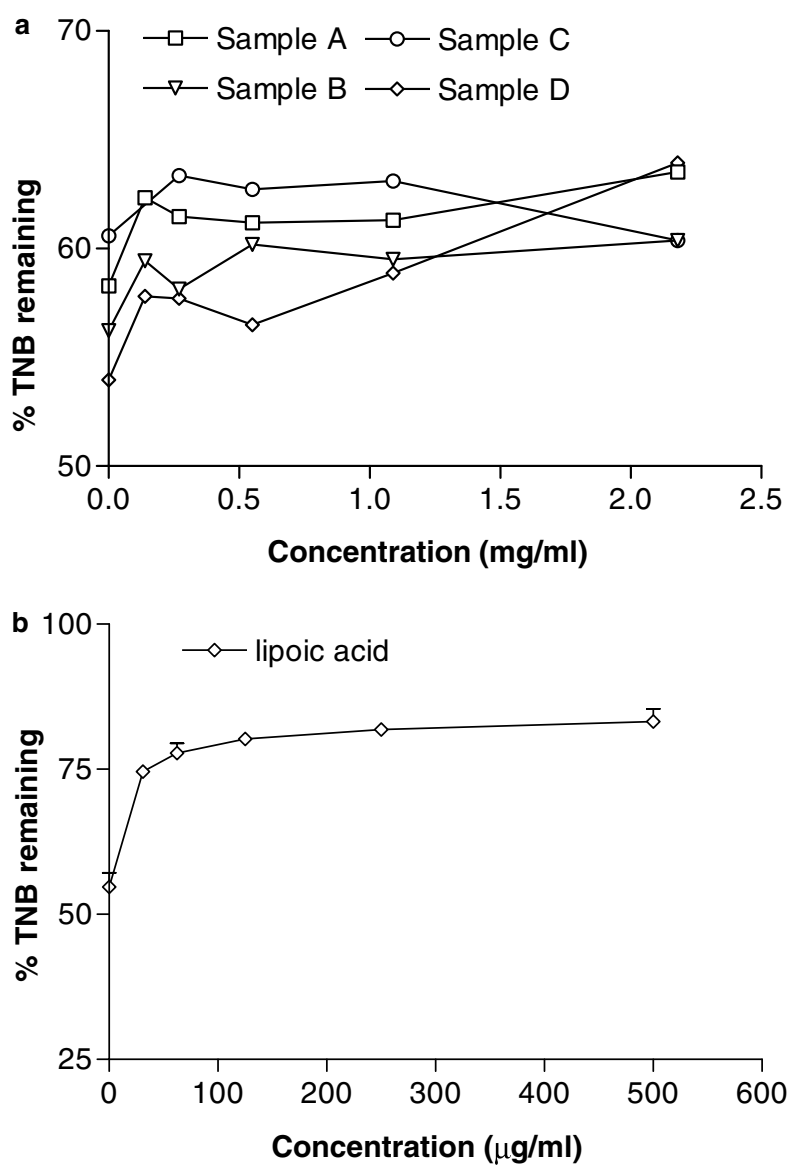

Fig. 6. Effects of tronchuda cabbage external leaves (a) and lipoic acid (b) on the oxidation of TNB by HOCl. The amount of TNB unchanged after incubation is calculated and expressed as percentage of the initial value. Values show means \pm SE from 3 experiments performed in triplicate.

However, some compounds have the ability to cause redox cycling of the metal ion required for hydroxyl generation, thus increasing the radical production, exhibiting pro-oxidant activity ( $\mathrm{Li} \& \mathrm{Xie}, 2000)$. In order to evaluate the pro-oxidant potential of the extracts, we omitted ascorbic acid. As can be seen in Fig. 5(b), all samples were a very effective substitute for ascorbic acid. Thus, these extracts may act as concentration-dependent pro-oxidants, that from sample $\mathrm{D}$ being the most active.

Damage to deoxyribose also occurs if the $\mathrm{Fe}^{3+}$-ascorbate- $\mathrm{H}_{2} \mathrm{O}_{2}$-induced generation of hydroxyl radicals is performed in the absence of EDTA, since omission of the chelator allows iron ions to bind directly to the sugar. Under such conditions, compounds inhibit deoxyribose degradation, not by reacting with hydroxyl radicals, but because they present ion-binding capacity and can withdraw the iron ions and render them inactive or poorly active in Fenton reactions (Payá, Halliwell, \& Hoult, 1992). The assay performed in the absence of EDTA showed that extracts from samples B and D were, to some extent, able to chelate iron ions in a con- centration-dependent manner, while those from samples $\mathrm{A}$ and $\mathrm{C}$ were practically ineffective (Fig. 5(c)).

Reactive oxygen species produced in vivo by activated phagocytic cells include $\mathrm{HOCl}$. Hypochlorous acid is produced in the organism at sites of inflammation by the oxidation of $\mathrm{Cl}^{-}$ions, catalysed by neutrophilderived myeloperoxidase, in the presence of $\mathrm{H}_{2} \mathrm{O}_{2}$ (Aruoma, Halliwell, Hoey, \& Butler, 1989). HOCl is a powerful oxidant, which reacts readily with many biologically important molecules. Thiol groups are easily oxidized by HOCl (Ching, De Jong, \& Bast, 1994). $\mathrm{HOCl}$ damages and induces target cell lysis, caused by sulfhydryl oxidation in plasma membrane proteins (Cochrane, 1991), inactivates $\alpha_{1}$-antiprotease, activates collagenase and gelatinase, depletes antioxidant vitamins, such as ascorbic acid, and inactivates antioxidant enzymes such as catalase (Payá et al., 1992; Visioli, Bellomo, \& Galli, 1998).

In the present assay, $\mathrm{HOCl}$ induces the oxidation of TNB $\left(\lambda_{\max }=412 \mathrm{~nm}\right)$ into DTNB $\left(\lambda_{\max }=325 \mathrm{~nm}\right)$ (Künzel, Zee, \& Ijzerman, 1996). An HOCl scavenger inhibits the oxidation of TNB by this species. When the antioxidant protection against damage by $\mathrm{HOCl}$ was evaluated, tronchuda cabbage lyophilised extracts exhibited a very weak antioxidant protective activity, with the exception of sample $D$, which showed some concentration dependent capacity (Fig. 6(a)). In the assayed conditions, lipoic acid was used as a reference compound, which scavenged $\mathrm{HOCl}$ effectively in a concentration- dependent manner, presenting a protective effect of $83 \%$ at $500 \mu \mathrm{g} / \mathrm{ml}$ (Fig. 6(b)).

In general terms, and according to the results obtained in all assays, sample A proved to be the one with highest antioxidant potential. This is not surprising, considering that it is the sample with the highest content of both phenolics and organic acids (Tables 2 and 3), which are known to have antioxidant activity (Madhavi, Singhal, \& Kulkarni, 1996). In addition, sample A has a high amount of acylated flavonols, namely caffeoyl derivatives (Table 2). These compounds are reported to have high scavenging ability due to the presence of an $O$-dihydroxy structure in the caffeoyl moiety, which confers great stability to the radical form and participates in the electron delocalisation (Braca et al., 2003). The presence of high contents of caffeic acid derivatives may also contribute to its lower pro-oxidant effect, because of the presence of a catechol ring (Galati, Sabzevari, Wilson, \& O’ Brien, 2002).

In opposition, sample $\mathrm{C}$ displayed the lowest antioxidant capacity, which can be ascribed to the presence of only vestigial amounts of phenolic compounds and to the minor organic acid content. Furthermore, this sample exhibited the lowest ascorbic acid content, when compared with the other samples. In spite of this, sample $\mathrm{C}$ showed a pro-oxidant effect, which might be related to the presence of other compounds in the extract. 
The great antioxidant activity presented by sample $\mathrm{D}$ may be attributed to its major content of ascorbic acid. However, the high amount of this organic acid can also explain the pro-oxidant effect observed in the deoxyribose assay performed in the absence of ascorbic acid.

Although the antiradical activity of phenolic compounds and organic acids is already known, it remains uncertain how a complex mixture, obtained from plant extracts, functions against reactive oxygen species, because other compounds of the mixture may potentiate or prevent the expected activity. In fact, this study indicates that phenolics and organic acids were not correlated with antioxidant capacity of the aqueous lyophilised extracts.

In conclusion, considering the results obtained and regarding the presence of several phenolics and organic acids in the aqueous lyophilised extracts of tronchuda cabbage external leaves, the scavenging activities observed against DPPH', superoxide radical, hydroxyl radical and hypochlorous acid are most probably due to the presence of these compounds, which contribute to the protective effects observed in the work herein. As far as we know, this is the first study concerning the antioxidant activity of tronchuda cabbage, and indicates that its external leaves can be used as good sources of antioxidants in our diet. This may be relevant in the prevention of diseases in which free radicals are involved.

\section{Acknowledgements}

The authors are grateful to Fundação para a Ciência e Tecnologia (POCI/AGR/57399/2004) for financial support of this work. Vendula Vrchovská is grateful to the European Union Erasmus/Socrates II Programme for a grant (MSM 0021620822).

\section{References}

Aruoma, O. I., Halliwell, B., Hoey, B. M., \& Butler, J. (1989). The antioxidant action of $n$-acetylcysteine: its reaction with hydrogen peroxide, hydroxyl radical, superoxide, and hypochlorous acid. Free Radical Biology and Medicine, 6, 593-597.

Bast, A., Haenen, G. R. M. M., \& Doelman, C. J. A. (1991). Oxidants and antioxidants: state of the art. American Journal of Medicine, 91(suppl. 3C), 2S-13S.

Beecher, C. W. W. (1994). Cancer preventive properties of varieties of Brassica oleracea: a review. American Journal of Clinical Nutrition, 59, 1166-1170.

Behl, C., \& Moosmann, B. (2002). Antioxidant neuroprotection in Alzheimer's disease as preventive and therapeutic approach. Free Radical Biology and Medicine, 33, 182-191.

Braca, A., Fico, G., Morelli, I., De Simone, F., Tomè, F., \& De Tommasi, N. (2003). Antioxidant and free radical scavenging activity of flavonol glycosides from different Aconitum species. Journal of Ethnopharmacology, 86, 63-67.

Ching, T.-L., De Jong, J., \& Bast, A. (1994). A method for screening hypochlorous acid scavengers by inhibition of the oxidation of 5-thio-2-nitrobenzoic acid: application to anti-asthmatic drugs. Analytical Biochemistry, 218, 377-381.

Cochrane, C. G. (1991). Cellular injury by oxidants. American Journal of Medicine, 91(suppl. 3C), 23S-30S.

Coulson, D. R., Siobhan, B., Cathal, J. F., Passmore, P., \& Johnston, J. A. (2004). $\beta$-Secretase activity in human platelets. Neurobiology of Aging, 25, S358.

du Toit, R., Volsteedt, Y., \& Apostolides, Z. (2001). Comparison of the antioxidant content of fruits, vegetables and teas measured as vitamin C equivalents. Toxicology, 166, 63-69.

Ferreres, F., Valentão, P., Llorach, R., Pinheiro, C., Cardoso, L., Pereira, J. A., et al. (2005). Phenolic compounds in external leaves of tronchuda cabbage (Brassica oleracea L. var. costata DC). Journal of Agricultural and Food Chemistry, 53, 2901-2907.

Fukumoto, L. R., \& Mazza, G. (2000). Assessing antioxidant and prooxidant activities of phenolic compounds. Journal of Agricultural and Food Chemistry, 48, 3597-3604.

Galati, G., \& O’Brien, P. J. (2004). Potential toxicity of flavonoids and other dietary phenolics: significance for their chemopreventive and anticancer properties. Free Radical Biology and Medicine, 37, 287-330.

Galati, G., Sabzevari, O., Wilson, J. X., \& O’ Brien, P. J. (2002) Prooxidant activity and cellular effects of the phenoxyl radicals of dietary flavonoids and other polyphenolics. Toxicology, 177, 91-104.

Guthrie, N., \& Kurowska, E. M. N. (2001). Anticancer and cholesterol-lowering activities of citrus flavonoids. In R. E. Wildman (Ed.), Handbook of nutraceuticals and functional foods (pp. 113-126). Boca Raton, FL: CRC Press.

Gyamfi, M. A., Yonamine, M., \& Aniya, Y. (1999). Free-radical scavenging action of medicinal herbs from Ghana Thonningia sanguinea on experimentally-induced liver injuries. General Pharmacology, 32, 661-667.

Halliwell, B. (1991). Reactive oxygen species in living systems: source, biochemistry and role in human disease. American Journal of Medicine, 91(suppl 3C), 14S-22S.

Halliwell, B., Aeschbach, R., Löliger, J., \& Aruoma, O. I. (1995). The characterization of antioxidants. Food and Chemical Toxicology, $33,601-617$.

Halliwell, B., Gutteridge, M. C., \& Aruoma, O. I. (1987). The deoxyribose method: a simple test tube assay for determination of rate constants for reactions of hydroxyl radicals. Analytical Biochemistry, 165, 215-219.

Hertog, M. G. L., Hollman, P. C., \& Van de Putte, B. (1993). Content of potentially anticarcinogenic flavonoids of tea infusions, wines and fruit juices. Journal of Agricultural and Food Chemistry, 41, $1242-1246$.

Hollman, P. C., Hertog, M. G. L., \& Katan, M. B. (1996). Role of dietary flavonoids in protection against cancer and coronary heart disease. Biochemical Society Transactions, 24, 785-789.

Jung, H. A., Park, J. C., Chung, H. Y., Kim, J., \& Choi, J. S. (1999). Antioxidant flavonoids and chlorogenic acid from the leaves of Eriobotrya japonica. Archives of Pharmacal Research, 22, 213218.

Künzel, J. K. v. F. D., Zee, J. v. d., \& Ijzerman, A. P. (1996). Radical scavenging properties of adenosine and derivatives in vitro. Drug Development Reserach, 37, 48-54.

Kurilich, A. C., Jeffery, E. H., Juvik, J. A., Wallig, M. A., \& Klein, B. P. (2002). Antioxidant capacity of different broccoli (Brassica oleracea) genotypes using the oxygen radical absorbance capacity (ORAC) assay. Journal of Agricultural and Food Chemistry, 50, 5053-5057.

Li, C., \& Xie, B. (2000). Evaluation of the antioxidant and pro-oxidant effects of tea catechin oxypolymers. Journal of Agricultural and Food Chemistry, 48, 6362-6366.

Llorach, L., Espín, J. C., Tomás-Barberán, F. A., \& Ferreres, F. (2003). Valorization of cauliflower (Brassica oleracea L. var. 
botrytis) by-products as a source of antioxidant phenolics. Journal of Agricultural and Food Chemistry, 51, 2181-2187.

Madhavi, D. L., Singhal, R. S., \& Kulkarni, P. R. (1996). Natural antioxidants. In D. L. Madhavi, S. S. Deshpande, \& D. K. Salunkhe (Eds.), Food antioxidants - technological, toxicological and health perspectives (pp. 73-76). New York: Marcel Dekker.

Miyake, Y., Shimoi, K., Kumazawa, S., Yamamoto, K., Kinae, N., \& Osawa, T. (2000). Identification and antioxidant activity of flavonoid metabolites in plasma and urine of eriocitrin-treated rats. Journal of Agricultural and Food Chemistry, 48, 3217-3224.

Ninfali, P., \& Bacchiocca, M. (2003). Polyphenols and antioxidant capacity of vegetables under fresh and frozen conditions. Journal of Agricultural and Food Chemistry, 51, 2222-2226.

Park, E. J., \& Pezzuto, J. M. (2002). Botanicals in cancer chemoprevention. Cancer and Metastasis Reviews, 21, 231-255.

Payá, M., Halliwell, B., \& Hoult, J. R. S. (1992). Interactions of a series of coumarins with reactive oxygen species. Scavenging of superoxide, hypochlorous acid and hydroxyl radicals. Biochemical Pharmacology, 44, 205-214.

Pietta, P., Simonetti, P., \& Mauri, P. (1998). Antioxidant activity of selected medicinal plants. Journal of Agricultural and Food Chemistry, 46, 4487-4490.

Pulido, R., Bravo, L., \& Saura-Calixto, F. (2000). Antioxidant activity of dietary polyphenols as determined by a modified ferric reducing/ antioxidant power assay. Journal of Agricultural and Food Chemistry, 48, 3396-3402.

Puppo, A. (1992). Effect of flavonoids on hydroxyl radical formation by Fenton-type reactions: influence of the iron chelator. Phytochemistry, 31, 85-88.

Racchi, M., Daglia, M., Lanni, C., Papetti, A., Govoni, S., \& Gazzani, G. (2002). Antiradical activity of water soluble components in common diet vegetables. Journal of Agricultural and Food Chemistry, 50, 1272-1277.
Sies, H. (1993). Strategies of antioxidant defence. European Journal of Biochemistry, 215, 213-219.

Silva, B. M., Andrade, P. B., Mendes, G. C., Seabra, R. M., \& Ferreira, M. A. (2002). Study of the organic acids composition of quince (Cydonia oblonga Miller) fruit and jam. Journal of Agricultural and Food Chemistry, 50, 2313-2317.

Silva, B. M., Andrade, P. B., Valentão, P., Ferreres, F., Seabra, R. M., \& Ferreira, M. A. (2004). Quince (Cydonia oblonga Miller) fruit (pulp, peel, and seed) and jam: antioxidant activity. Journal of Agricultural and Food Chemistry, 52, 4705-4712.

Stoewsand, G. S. (1995). Bioactive organosulfur phytochemicals in Brassica oleracea vegetables - a review. Food and Chemical Toxicology, 33, 1537-1543.

Tseng, T.-H., Kao, E.-S., Chu, C.-Y., Chou, F.-P., Lin Wu, H.-W., \& Wang, C.-J. (1997). Protective effects of dried flower extracts of Hibiscus sabdariffa L. against oxidative stress in rat primary hepatocytes. Food and Chemical Toxicology, 35, 1159-1164.

Valentão, P., Fernandes, E., Carvalho, F., Andrade, P. B., Seabra, R. M., \& Bastos, M. L. (2001). Antioxidant activity of Centaurium erythraea infusion evidenced by its superoxide radical scavenging and xanthine oxidase inhibitory activity. Journal of Agricultural and Food Chemistry, 49, 3476-3479.

Valentão, P., Fernandes, E., Carvalho, F., Andrade, P. B., Seabra, R. M., \& Bastos, M. L. (2002). Antioxidant properties of cardoon (Cynara cardunculus L.) infusion against superoxide radical, hydroxyl radical, and hypochlorous acid. Journal of Agricultural and Food Chemistry, 50, 4989-4993.

Visioli, F., Bellomo, G., \& Galli, C. (1998). Free radical-scavenging properties of olive oil polyphenols. Biochemical and Biophysical Research Communications, 247, 60-64.

Yen, G.-C., \& Chen, H.-Y. (1995). Antioxidant activity of various tea extracts in relation to their antimutagenicity. Journal of Agricultural and Food Chemistry, 43, 27-32. 